www.jmscr.igmpublication.org Impact Factor 5.244

Index Copernicus Value: 83.27 ISSN (e)-2347-176x ISSN (p) 2455-0450 crossref DOI: _https://dx.doi.org/10.18535/jmscr/v4i12.27

\title{
The Prevalence of Osteoporosis and Osteopenia in Persons above 50 Years Attending a Tertiary Care Hospital in South India
}

\author{
Authors \\ Hemalata $^{1}$, Reeba M Mani ${ }^{2}$, Sreekala V K ${ }^{3}$ \\ ${ }^{1,2}$ Assistant Professor, Dept of Physical Medicine and Rehabilitation, Govt Medical College Kozhikode, \\ Kerala \\ ${ }^{3}$ Principal, Govt Medical College Ernakulam, Kalamassery, Kerala \\ Corresponding Author \\ ${ }^{1}$ Hemalata \\ Assistant Professor, Dept of Physical Medicine and Rehabilitation, \\ Govt. Medical College Kozhikode, Kerala, India 673008 \\ Email: drhemalataviswan@gmail.com,Mob; +919447459101
}

\begin{abstract}
BACKGROUND: The prevalence of osteoporosis among the elderly Indian population is increasing with the increasing longetivity of age. This can predispose to osteoporotic fractures and is a major cause for morbidity and also mortality. Early detection of Osteoporosis and appropriate timely treatment may reduce the clinical symptoms, thus reducing morbidity and improve the quality of life too.
\end{abstract}

\section{OBJECTIVE:}

1. To assess the prevalence of osteoporosis among the patients above the age of 50 years who attended the outpatient department of a tertiary level multispecialty hospital

2. To study the associated demographic factors

METHODS: The identified patients were screened using the Bone Mineral Density (BMD) as the standard. This was measured using the Calcaneal Quantitative Ultra Sound (QUS). A structured questionnaire was used to identify the sociodemographic profile of the patients.

SAMPLE-SIZE-201 patients of age 50 years and above

RESULTS: It was found that osteoporosis and osteopenia were highly prevalent in persons above 50 yrs presenting with various conditions of musculoskeletal pains (osteoporosis 50\% and osteopenia 36\%). There was $62 \%$ of the patients who belonged to the age group 50-60years. More females were detected with osteoporosis (53\%) and osteopenia (33\%), while only 34\% of the males were detected to have osteoporosis and $52 \%$ had osteopenia. It was also noted that substantial propotion of this population group had low exposure to sunlight (65\%). Positive association was found between increased age, female gender, menopause, low educational status, hysterectomy ststus and low Bone Mineral Density Score.

CONCLUSION: It was found that osteoporosis and osteopenia were highly prevalent in persons above 50 yrs presenting with various conditions of musculoskeletal clinical problems. Low back pain and knee pain were the common musculoskeletal presentations. Thus early detection of osteoporosis and appropriate and timely management may reduce morbidity, improve symptom control and improve quality of life in these patients KEYWORDS: Osteoporosis; Osteopenia; Bone Mineral Density. 


\section{INTRODUCTION}

Osteoporosis poses one of the major health problems associated with significant morbidity, mortality and socioeconomic burden [1] Osteoporosis is characterized by low bone mass with micro architectural deterioration of bone tissue leading to enhanced bone fragility, thus increasing the susceptibility to fracture. Although exact numbers are not available, based on available data and clinical experience, an estimated 50 million Indians may be affected, as reported by Malhotra et al ${ }^{[2]}$.

The greatest bone loss occurs in women during perimenopause and is associated with estrogen insufficiency, a condition of menopause. ${ }^{[3]}$. There have been several epidemiologic studies and surveys on the prevalence of osteoporosis and related risk factors in communities. ${ }^{[4]}$ In India, the precise figures on the prevalence of osteoporosis are not available at present. However, in other studies, it is estimated that more than 61 million Indians have osteoporosis; of these, $80 \%$ patients are females. ${ }^{[5] ~[6]}$

An age-dependent decline in Bone Mineral Density (BMD) was seen in both women and men over the age of 50 years and the normative database for BMD in Indian population using digital X-ray radiogrammetry. was stated by Pande et al ${ }^{[7]}$. Aggarwal et al ${ }^{[3]}$ has stated that Osteoporosis has numerous medical implications and a huge economic impact. .Evaluation of BMD through absorptiometry is recommended. DEXA (dual energy X-ray absorptiometry) as the gold standard to assess BMD. ${ }^{[3]}$, Calcaneal Quantitative Ultrasound (QUS) devices can be used to examine the BMD and the $T$-score threshold that would be appropriate to identify people at risk of osteoporosis using QUS [8] Calcaneal-QUS technique could increase substantially the accessibility to a reliable bone osteoporosis risk evaluation, ${ }^{[9]}$

Elderly people are at a high risk of osteoporosis, hence Vitamin D3 and Calcium supplements are recommended for fracture prevention ${ }^{[10]}$ This can be administered either alone or together, but prevention of fractures in previously mobile elderly has to be evaluated further. Osteoporotic fractures in India occur commonly in both sexes, and may occur at a younger age than in the West Recently published data have clearly demonstrated widespread vitamin D deficiency across India, at all ages and in both sexes, particularly in the urban areas. Poor sunlight exposure, skin pigmentation and a vitamin Ddeficient diet are some obvious causes for this finding ${ }^{[2]}$. however, the high prevalence of vitamin $\mathrm{D}$ deficiency is a major factor in the low BMD and poor bone health of Indians. Healthy lifestyle (diet, exercise and sunlight exposure) can have a major positive impact on the bone metabolism and bone health of Indians. These public health measures are recommended for the population at large as they are efficacious, safe and cost-effective. The peak bone mass of the population can be increased significantly by appropriate and timely intervention in children.

WHO has defined osteoporosis ${ }^{[8]}$ as Bone Mineral Density 2.5 SD (standard deviation) below the mean bone mass of young normal adults. Normal BMD is T-score $\geq-1$; Osteopenia $\mathrm{T}$ - score between -1 and -2.5 Osteoporosis - Tscore $\leq-2.5$; Severe osteoporosis $-\mathrm{T}$-score $\leq$ 2.5 with fractures. ${ }^{[11]}$.

\section{MATERIALS \& METHODS}

A cross sectional study of patients, aged $50 \mathrm{yrs}$ and above with various conditions of musculoskeletal pain were included for study over in Dept. of Physical Medicine and Rehabilitation (PMR), Govt Medical College, Kotttayam; Kerala. After taking informed consent both males and females above $50 \mathrm{yrs}$ of age presenting with various conditions of non autoimmune musculoskeletal pains were included in the study. Patients who had diseases of kidney \& liver, ,chronic malabsorptive conditions., thyroid and parathyroid disorders, malignancies., CNS disorders, patients already on Calcium supplements and on glucocorticoids were excluded. 
The Bone Mineral Density t-score was recorded using Calcaneal QUS.A pre designed pre tested questionaire was used to record the scores and demographic information .

\section{STATISTICAL ANALYSIS}

Results were analysed using SPSS 16 version. Paired t- test, Wilcoxin signed rank test,chisquare tests were used to analyse the data.

\section{RESULTS}

As depicted in graph-1, out of the total of 201 patients studied, 100 patients (t-score $\leq-2.5$ ) had Osteoporosis.

72 patients ( $\mathrm{t}$ score between -1 and -2.5 ) had Osteopenia, and the rest of 29 patients ( $\mathrm{t}$ score $\geq-$ 1) had normal Bone Mineral Density (BMD).

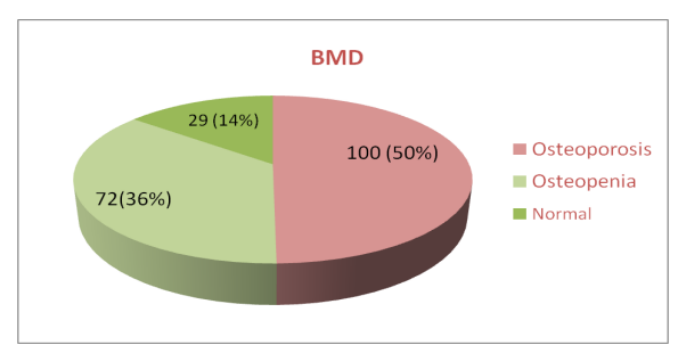

Graph No :1 BMD Distribution.

Out of 201 patients, 124 patient were among the age group of 50-60 years (62\%), 55 were among age group of 61-70 years (27\%) and 23 where above $70 y$ rs of age (11\%).Out of 201 patients studied, 166 were females $(83 \%)$ and 35 were males (17\%). Out of 166 females, 88 female $(53 \%)$ were osteoporotic and 54 female $(33 \%)$ were osteopenic and 24 females (14\%) were normal. Out of 35 males 12 males (34\%) Osteoporotic and 18males (52\%) were Osteopenic and 5males (14\%) were normal. This is displayed in Table No.1

Table No.1: BMD Distribution according to gender.

\begin{tabular}{|l|l|l|l|l|}
\hline Gender & Osteoporosis & Osteopenia & Normal & Total \\
\hline Male & $12(34 \%)$ & $18(52 \%)$ & $5(14 \%)$ & 35 \\
\hline Female & $88(53 \%)$ & $54(33 \%)$ & $24(14 \%)$ & 166 \\
\hline
\end{tabular}

\section{OCCUPATION}

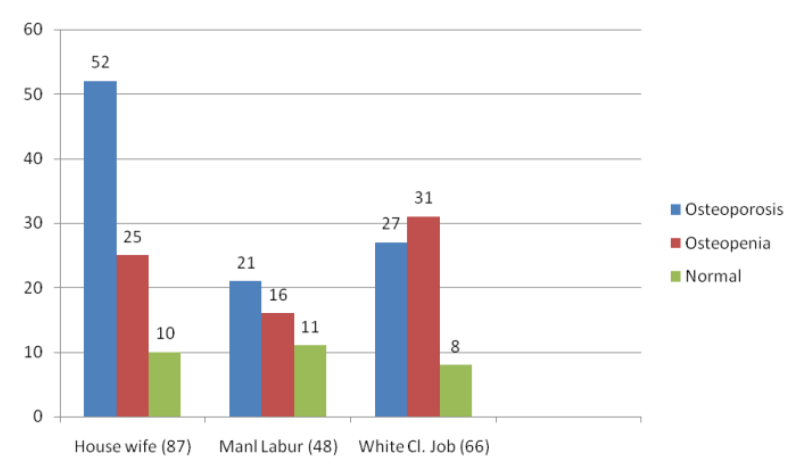

Graph No. 2 Different Types of occupation in the Normal, Osteopenia and Osteoporosis group

In the graph No.2, out of the total population studied 87 were house wives, of which 52 were Osteoporotic (58\%) and 25 were osteopenic (28\%). Among 66 white collar jobs, 27 were osteporotic (41\%) and 31 were osteopenic (47\%).Among the 48 manual labourers, 21 were osteoporotic (44\%), and 16 were osteopenic $(33 \%)$.

\section{EDUCATIONAL STATUS}

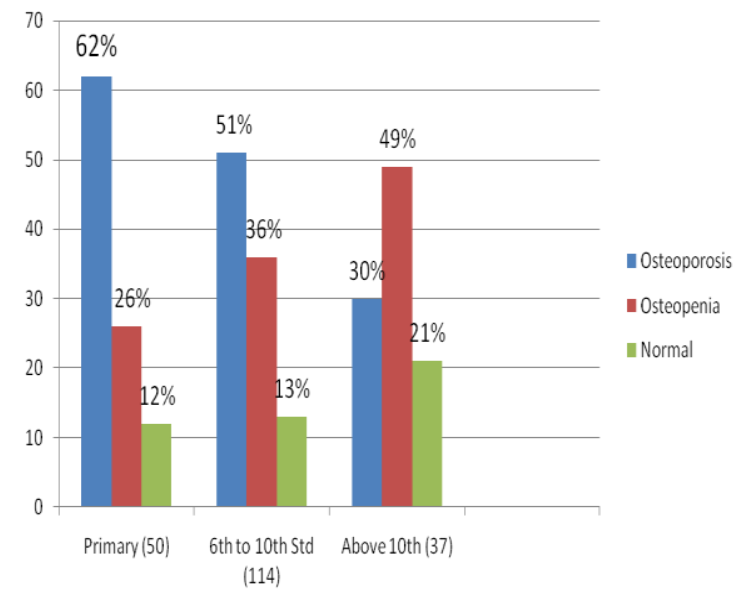

Graph No 3 : Distribution of educational status

Out of total patients studied, 114 patents had educational status up to 10 standard, 50 patient had studied up to $5^{\text {th }}$ std and 37 patients had higher education beyond $10^{\text {th }}$ standard. As shown in Graph No.3, among the patients who had studied up to $\mathrm{X}^{\text {th }}$ std were -114 , of which $51 \%$ were Osteoporotic and $36 \%$ were osteopenic. Among the patients who had studied up to $5^{\text {th }}$ std were-50, 62\% were Osteoporotic and 26\% were 
osteopenic. Among the patients of above $10^{\text {th }}$ std37, 30\% were Osteoporotic and 49\% were osteopenic.

\section{HYSTERECTOMY STATUS}

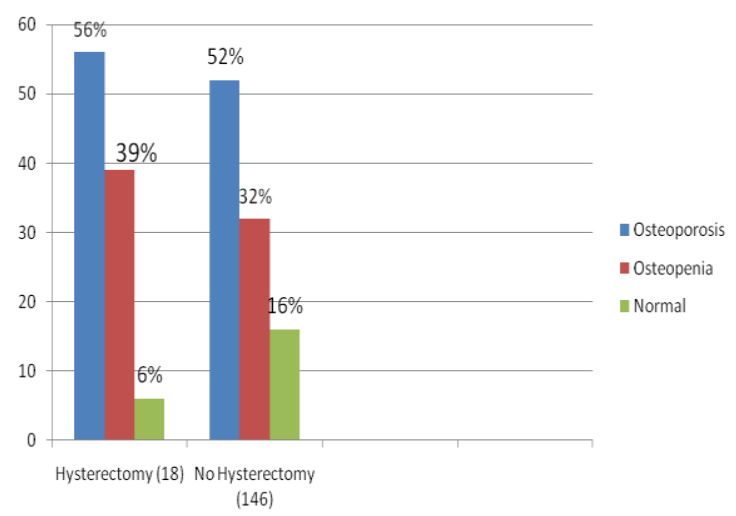

Graph No. 4- The distribution among the Hysterectomy and the non-hysterectomy women

As shown in Graph No.4, 18 females had undergone hysterectomy. $56 \%$ among them were osteoporotic and $39 \%$ were oesteopenic. Among the 146 female who had not undergone hysterectomy, 52\% were osteoporotic and $32 \%$ were osteopenic.

\section{EXPOSURE TO SUNLIGHT}

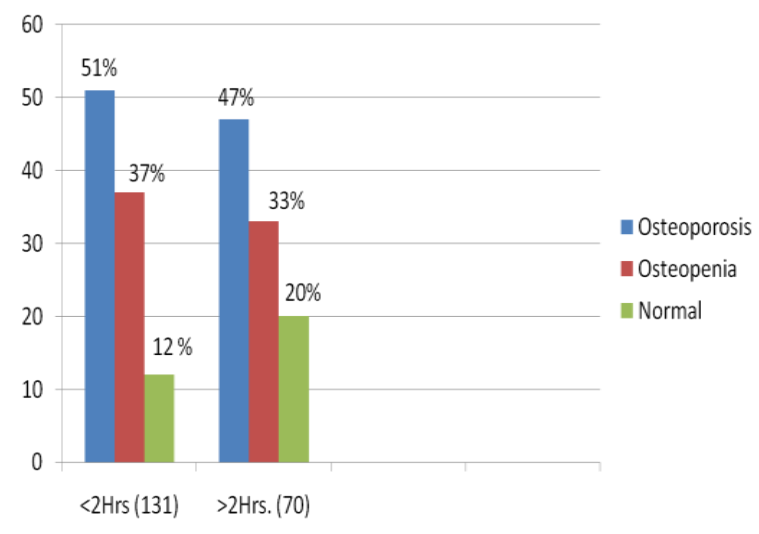

Graph No.5- Distribution depending on the duration of exposure to sunlight

As shown in Graph No. 5, 131 patients had daily exposure to sunlight for less than 2 hours. Among them $51 \%$ were osteoporotic and $37 \%$ were osteopenic, $12 \%$ were normal. 70 patients had daily exposure to sunlight for more than 2 hours. Out of them $47 \%$ were osteoporotic and $33 \%$ were osteopenic, $20 \%$ were normal

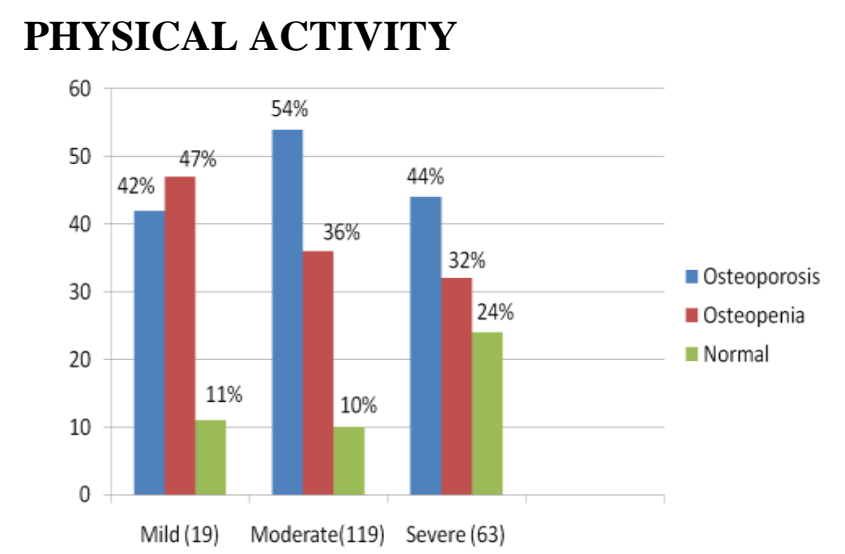

Graph No. 6 Distribution depending on the severity of Physical Activity

As shown in Graph No. 6, based on physical activity level -119 patients had moderate physical activity level of which 54\% osteoporotic and $36 \%$ oestepenic and 10\% had normal BMD. 63 patient had high level of physical activity of whom $44 \%$ were osteoporotic and $32 \%$ were oestepenic $(24 \%$ Normal). 19 patients had low level of physical activity of whom $42 \%$ were osteoporotic, $47 \%$ were osteopenic (11\% Normal) .

\section{MUSCULOSKELETAL PAIN}

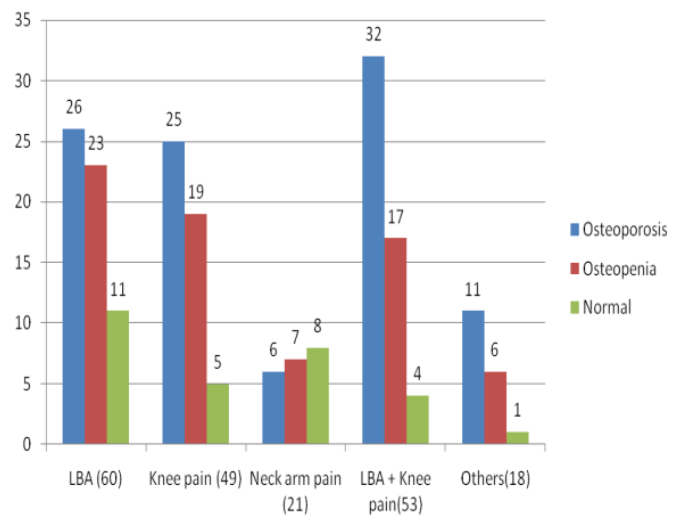

Graph No.7 The distribution of Musculoskeletal Pain sites

As Depicted in Graph No7, majority of the patients (60) had low back pain with 26 patiets (43\%) having osteoporosis and 26 patients(43\%) having osteopenia and 11 normal patient(18\%).53 patients had combined low back pain and knee pain - of whom 32 were Osteoporotic (60\%); 17 were Osteopenic (32\%). The patients with knee pain constituted 49 patients of whom 25 were 
Ostepoporotic (51\%);19 were Osteopenic (39\%). 21 patients had neck arm pain - of whom 6 were Osteoporotic (29\%) and 8 were Osteopenic (38\%).

\section{CONCLUSIONS}

In the above study, it was found that osteoporosis and osteopenia are highly prevalent in persons above $50 \mathrm{yrs}$ presenting with various conditions of musculoskeletal pains (osteoporosis 50\% and osteopenia 36\%). It was found that low back pain, and combined low back pain with knee pain were the common presentations. Majority of the population have very low exposure to sunlight (65\%). It was found that Calcaneal QUS can be used as a baseline screening tool to assess BMD. Positive association was found between increased age, female gender, menopause, low educational status, hysterectomy status \& low BMD Score.

Limitations of the Study: Small sample size. It was a tertiary hospital based study.

The early detection of Osteoporosis will go a long way to prevent osteoporotic fractures and related morbidity thereby improving the quality of life of our geriatric population.

\section{ACKNOWLEDGEMENTS}

To all members of the team involved in this study

\section{REFERENCES}

1. Delmas PD, Fraser M. Strong bones in later life: Luxury or necessity? Bull World Health Organ 1999;77:416-22.

2. N .Malhotra, A. Mithal, Osteoporosis in Indians ; Indian J . Med. Res 127 , March 2008, pp263-268

3. Aggarwal N, Raveendran A, Khandelwal N, Sen RK, Thakur J S, Dhaliwal LK, Singla V, Manoharan SR. Prevalence and related risk factors of osteoporosis in periand postmenopausal Indian women. J Midlife Health $2011 ; 2: 81-5$

4. Inanici-Ersöz F, Gökçe-Kutsal Y, Oncel S, Eryavuz M, Peker O, Ok S. A multicenter case control study of risk factors for low tibial speed of sound among residents of urban areas in Turkey. Rheumatol Int 2002;22:20-6.

5. Joshi VR, Mangat G, Balakrishnan C, Mittal G. Osteoporosis-approach in Indian scenario. J Assoc Physicians India 1998; 46:965-7.

6. Rao H, Rao N, Sharma LR. A clinical study of bone mineral density using heel ultra-densitometer in Southern Maharashtra. Indian J Orthop 2003;37:9.

7. Pande KC, Veeraji E, Pande SK. Normative reference database for bone mineral density in Indian men and women using digital X-ray radiogrammetry. J Indian Med Assoc 2006;104:288-91

8. M L Frost, G L Blake, I. Fogelman; Can the WHO criteria for diagnosing osteoporosis be applied to calcaneal quantitative ultrasound? ; Osteoporosis international ; May 2000, Vol 11, issue 4, pp321-330

9. Adami, S., Giannini, S., Giorgino, R. et al., The effect of age, weight, and lifestyle factors on calcaneal quantitative ultrasound: the ESOPO study; Osteoporos Int (2003) 14: 198. doi:10.1007/s00198002-1352-5

10. Philip Sambrrok, the Record trial group. Oral vitamin D3 and calcium for secondary prevention of low trauma fractures in elderly people (Randomised Evaluation of Calcium or Vitamin D, RECORD) : a randomized placebo controlled trial. The Lancet, vol 365 , issue 9471, 7-13 May 2005 1621-1628

11. Ethel $\mathrm{S}$ Siris et al; Identification and fracture outcomes of undiagnosed low bone mineral density in post menopausal women. Results from the National osteoporosis Risk assessment.; JAMA Dec $122001 ; 286(22): 2815-2822$. 